TRANI, P.E.; NOVO, M.C.S.S.; CAVALLARO JÚNIOR, M.L.; TELLES, L.M.G. Produção de mudas de alface em bandejas e substratos comerciais. Horticultura Brasileira, Brasília, v.22, n.2, p.290-294, abril-junho 2004.

\title{
Produção de mudas de alface em bandejas e substratos comerciais
}

\author{
Paulo E. Trani1'; Maria do Carmo S.S. Novo ${ }^{1}$; Mário L. Cavallaro Júnior ${ }^{2}$; Luciana M.G. Telles ${ }^{3}$
}

${ }^{1}$ Instituto Agronômico, C. Postal 28, 13001-970 Campinas-SP; E-mail: petrani@bestway.com.br; ${ }^{2}$ UNESP, campus Ilha Solteira, C. Postal 31, 15385-000 Ilha Solteira-SP; ${ }^{3}$ UNESP, campus Botucatu, C. Postal 237, 18603-970 Botucatu, SP

\section{RESUMO}

Avaliou-se o desenvolvimento de mudas de alface (Lactuca sativa L. cv Vera) produzidas em diferentes bandejas de poliestireno e em quatro substratos comerciais em um experimento em Campinas (SP), sob cultivo protegido, de 15/01 a 13/02/03. Os tratamentos consistiram na combinação fatorial de tipos de substratos (Plantmax HA, Hortimix folhosas, Golden Mix 47 e Vida Verde Tropstrato hortaliças) e tamanhos de células em bandejas de poliestireno (200 e 288 células). O experimento foi disposto inteiramente ao acaso, com as parcelas subdivididas para época de avaliação, com três repetições sendo cada uma constituída de uma bandeja. As avaliações foram realizadas aos cinco, dez, quinze e vinte dias após a germinação sendo retiradas em cada uma, ao acaso, vinte plantas de cada bandeja. Foram avaliados suas alturas, número de folhas, estabilidade do torrão e a área foliar. O substrato Plantmax proporcionou aos 15 e 20 dias após a germinação, mudas de alface mais desenvolvidas em relação aos outros substratos. Independente do tipo de substrato, as bandejas de 200 células mostraram-se melhores que as de 288 células quanto ao número de folhas e área foliar por ocasião do transplante (20 dias).

Palavras-chave: Lactuca sativa L., substrato, bandeja de poliestireno.

\begin{abstract}
Production of lettuce seedlings in different trays and commercial substrates
\end{abstract}

The effect of four commercial substrates in polystyrene trays with 200 and 288 cells, was evaluated on the production of seedlings of lettuce (Lactuca sativa cv. Vera) in a plastic greenhouse, from 15/ 01 to 13/02/03, in Campinas, São Paulo State, Brazil. The treatments consisted of factorial combinations of four commercial substrates (Plantmax HA, Hortimix folhosas, Golden Mix 47 and, Vida Verde Tropstrato hortaliças) and two cell sizes (200 and 288 cells). The experimental design was a randomized complete design, with the plots split with each part subdivided for the evalution time, with three repetitions, each beign made up of a tray. At 5; 10; 15 and 20 days after germination, twenty random plants from each plot were evaluated for their stem height, number of leaves, clod stability of substrate and foliar area. Fifteen and twenty days after germination, the lettuce seedlings grown in Plantmax presented better development characteristics than other substrates. Seedlings produced on trays with 200 cells presented greater number of leaves and bigger leaf areas than those produced on 288 cells trays.

Keywords: Lactuca sativa L., commercial substrate, polystyrene tray.

\section{(Recebido para publicação em 16 de abril de 2003 e aceito em 30 de março de 2004)}

$\mathrm{O}$ sucesso de uma produção agríco la começa pela obtenção de mudas com boa qualidade pois aquelas mal formadas darão origem a plantas com produção abaixo de seu potencial genético. Grande parte dos 8.000 ha plantados anualmente com alface no estado de São Paulo, é suprida por mudas fornecidas por viveiristas profissionais, sendo preparadas com substratos comerciais em bandejas de poliestireno expandido. $\mathrm{O}$ uso de bandejas economiza substrato e espaço dentro da casa-de-vegetação, produz mudas de boa qualidade com alto índice de pegamento após o transplante, além de necessitar de menos tratamentos fitossanitários (Oliveira et al, 1993). A uniformidade das mudas e a economia de água é maior e foi observado também que ocorre menos danos às raízes no momento do transplante (Cañizares et al., 2002).

Em São Paulo, a produção artesanal de substratos pelos próprios produtores, a exemplo de algumas regiões do País, é incipiente devido ao alto custo da mão de obra e à boa disponibilidade e facilidade de acesso a empresas produtoras, entre outros fatores. No mercado nacional estão disponíveis diversos substratos com formulações e propriedades praticamente desconhecidas sendo indistintamente recomendados para diferentes espécies agrícolas.

Existe ainda, no momento, um debate técnico entre produtores de mudas e produtores de alface sobre o tamanho ideal de bandeja. Na produção de mudas de alface prevalecem bandejas com 200 e 288 células. Os viveiristas têm preferência por bandejas com maior número de células para melhor aproveitamento dos substratos e do espaço das estufas. Entretanto, os produtores procuram adquirir mudas de melhor qualidade, com bom enraizamento e desenvolvimento de folhas, de maneira a permitir maior amplitude no período de transplante das bandejas para o campo. O tamanho das células dos recipientes e o tipo de substrato são aspectos primordiais a serem estudados para a obtenção de mudas de qualidade pois afetam diretamente o desenvolvimento e a arquitetura do sistema radicular bem como o fornecimento de nutrientes às mudas (Echer et al., 2000).

Em relação a cultivares de alface, considera-se que a 'Vera', do tipo crespa, corresponda a cerca de 40 a $50 \%$ daquelas cultivadas no verão, apresentando boa resistência ao pendoamento e a diversas doenças, tendo boa aceitação pelo público consumidor, conforme indicações dos revendores de sementes de hortaliças da região de Campinas.

O presente trabalho teve como objetivo avaliar o desenvolvimento de mudas de alface cv. Vera, produzidas em bandejas de poliestireno expandido, de 200 e 288 células, e em quatro substratos comerciais, sob cultivo protegido. 


\section{MATERIAL E MÉTODOS}

O experimento foi realizado em estufa plástica com cobertura de polietileno transparente, com espessura de $150 \mathrm{~mm}$ e laterais cobertas com tela tipo sombrite de $2 \mathrm{~mm}$ de abertura, desde a superfície do solo até $2 \mathrm{~m}$ de altura, localizada na Estação Experimental do Instituto Agronômico, em Campinas, de 15/01 a 13/02/03.

Os tratamentos consistiram na combinação fatorial de quatro tipos de substratos [Plantmax HA (composto por casca de pinus compostada, turfa, carvão vegetal e vermiculita), Hortimix folhosas (casca de pinus bio estabilizada, vermiculita e calcário dolomítico), Golden Mix 47 (Fibra de coco de textura fina) e Vida Verde Tropstrato hortaliças (casca de pinus compostada, turfa e carvão vegetal)] e dois tamanhos de células em bandejas de poliestireno (200 e 288 células). Foram realizadas análises químicas e granulométricas dos substratos (Tabela 1).

Para se obter maior uniformidade na profundidade de semeadura, foram utilizados marcadores apropriados para cada tamanho de célula. Sementes peletizadas de alface cv Vera foram semeadas no dia 15/01/03 sendo colocada uma unidade por célula. Após a semeadura, as bandejas foram sustentadas por bancadas de madeira que ficavam a uma distância de $0,80 \mathrm{~m}$ do solo o que facilitou a poda natural das raízes pela luz, a irrigação e a movimentação das bandejas evitando possíveis danos às mudas. As fertirrigações foram realizadas duas vezes por semana iniciandose cinco dias após a emergência (logo após a primeira avaliação). Os fertilizantes e doses, conforme recomendações dos fabricantes foram: Golden Mix: $0,35 \mathrm{~g} \mathrm{~L}-1$ de nitrato de cálcio, $0,46 \mathrm{~g} \mathrm{~L}^{-1}$ de nitrato de magnésio e $1 \mathrm{~g} \mathrm{~L}^{-1}$ de 20 10-20; Hortimix: $1 \mathrm{~g} \mathrm{~L}^{-1}$ de 20-10-20, fosfato monopotássico, nitrato de potássio, nitrato de cálcio e nitrato de magnésio; Plantmax: $1 \mathrm{~g} \mathrm{~L}^{-1}$ de 13-4013; Vida Verde: $10 \mathrm{ml} \mathrm{L}^{-1}$ de soluções de macro e micronutrientes conforme preconizado por Furlani et al. (1999). Na última semana, exceto no tratamento com Plantmax, foram realizadas duas

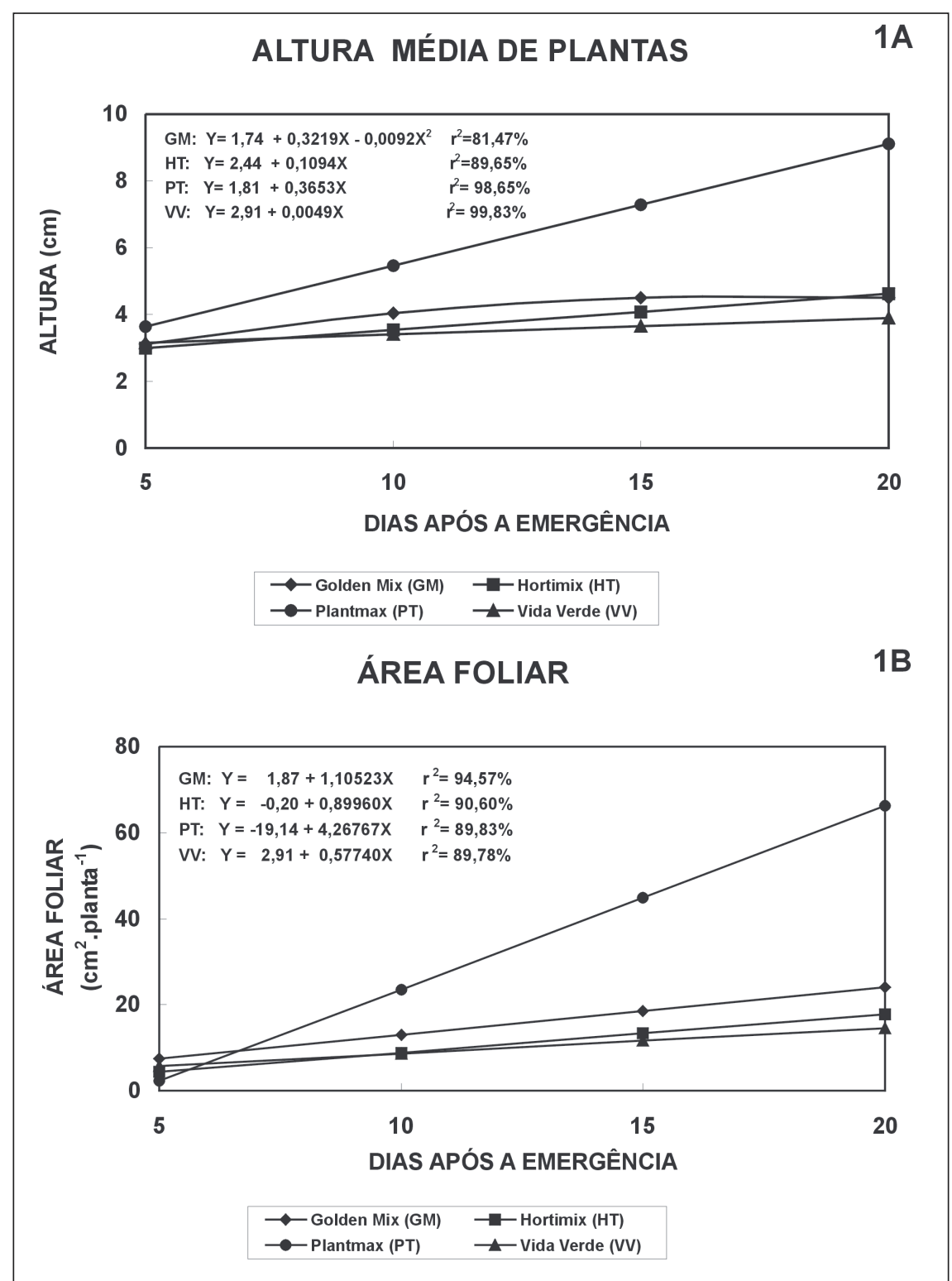

Figura 1. Altura média (1A) e área foliar (1B) de mudas de alface nos diferentes substratos aos cinco, dez, quinze e vinte dias após a emergência. Campinas, IAC, 2003.

irrigações com Nitrophoska A na dose de $1 \mathrm{ml} \mathrm{L}{ }^{-1}$. Em todas as fertirrigações, em cada bandeja foram aplicadas 600 $\mathrm{ml}$ das soluções nutritivas.

$\mathrm{O}$ experimento foi disposto inteiramente ao acaso, com três repetições sendo cada repetição constituída de uma bandeja. As avaliações foram realizadas aos cinco, dez, quinze e vinte dias após a germinação. Em cada avaliação foram retiradas, ao acaso, vinte plantas de cada bandeja sendo avaliados a altura, o número de folhas e a estabilidade do torrão. A estabilidade do torrão considerando a sua coesão ao retirar a planta do recipiente, foi avaliada conforme escala de notas adaptada de Gruszynski
(2002) onde $1=$ mais de $50 \%$ do torrão ficou retido no recipiente; $2=0$ torrão se destacou do recipiente mas não permaneceu coeso e $3=$ todo o torrão foi destacado do recipiente e mais de $90 \%$ dele permaneceu coeso. Para a determinação da área foliar, todas as plantas amostradas em cada época foram acondicionadas em sacos plástico e mantidas sob refrigeração para posterior leitura em integrador de área foliar.

A análise de variância dos resultados foi feita de acordo com o método para experimentos em parcelas subdivididas empregando-se o teste de Tukey para a comparação entre as médias dos substratos e do número de células por 


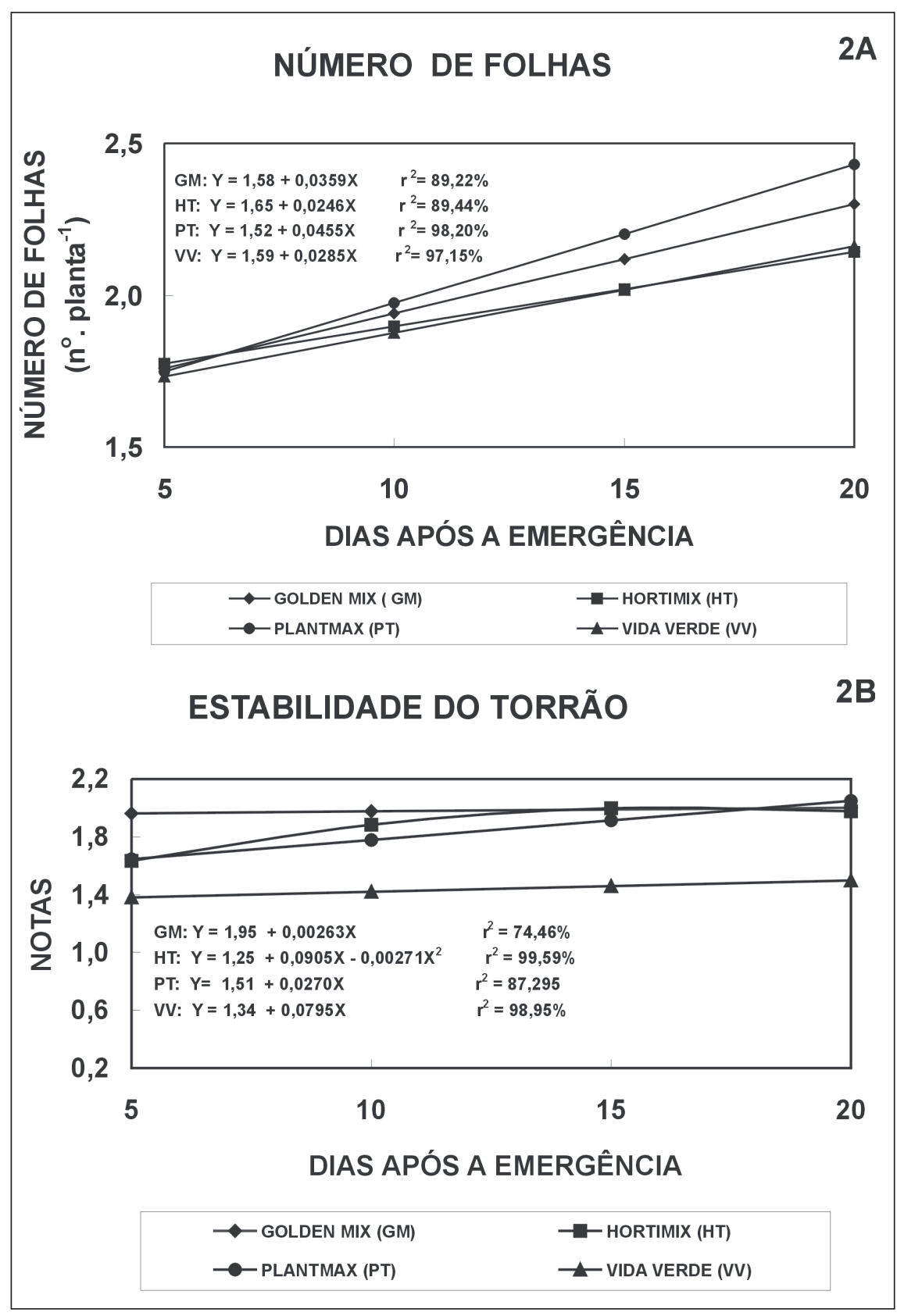

Figura 2. Número médio de folhas e estabilidade do torrão de mudas de alface nos diferentes substratos aos cinco, dez, quinze e vinte dias após a emergência. Os dados foram transformados em raiz de $\mathrm{x}+1$ para a realização da análise estatistica. Campinas, IAC, 2003.

bandeja e regressão polinomial para os efeitos de épocas. Os dados de número médio de folhas e notas de estabilidade do torrão para normalização da distribuição foram transformados em raiz de $\mathrm{x}+1$ para análise estatística.

\section{RESULTADOS E DISCUSSÃO}

Houve diferença estatística quanto à altura média de plantas e área foliar (Figuras 1A e 1B) nas quatro épocas de avaliação em relação ao tipo de substrato empregado. A partir de dez dias após a emergência, as mudas que cresceram no Plantmax mostraram-se superiores aos demais substratos. Dados de Sebraema (sd) relataram que, por ocasião do transplante das mudas, que ocorre após 2025 dias, as plantas devem estar com, aproximadamente $5 \mathrm{~cm}$ de altura. Plantmax aos quinze dias já apresentava mudas com altura superior a $5 \mathrm{~cm}$ mas, Vida Verde, mesmo aos vinte dias não alcançou essa altura (Figura $1 \mathrm{~A}$ ). Luz et al. (2000) observaram que as mudas de alface cv Verônica, crescidas em Plantmax, aos 30 dias após a semeadura, estavam com $6,09 \mathrm{~cm}$. Acreditase que esta diferença nas altura das mudas em relação ao presente experimento seja devida ao potencial genético das cultivares e à fatores climáticos. Nos outros três substratos empregados, exceto para Golden Mix, houve aumento linear na altura média das plântulas em função do tempo. Para o Golden Mix foi estimado que ocorreria aumento na altura média até os 17,5 dias.

Nas quatro épocas de avaliação observou-se que a área foliar aumentou linearmente em função do tempo e foi maior com o uso de Plantmax (Figura 1B).

Embora no substrato Golden Mix tenha sido observado excelente emergência, este não se revelou bom substrato quanto ao desenvolvimento das plantas. Segundo Pragana (1998), citado por Silveira et al. (2002) e Carrijo et al. (2002), Golden Mix apresenta baixo teor de nutrientes sendo necessário misturá-lo com outro material ou fornecê-lo de acordo com as necessidades das espécies adicionando adubos em pré-plantio ou, principalmente, em fertirrigação. No presente trabalho, embora seguindo as recomendações do fabricante, a fertirrigação utilizada para o substrato Golden Mix não foi suficiente para proporcionar maior crescimento das mudas de alface. Na última época de avaliação foi observada leve deficiência de nitrogênio nas mudas crescidas nesse substrato.

Apenas a partir dos dez dias, o tipo de substrato começou a interferir no desenvolvimento das folhas de mudas de alface quanto ao número de folhas. Mudas crescidas em Plantmax e em Golden Mix foram estatísticamente superiores àqueles com Vida Verde e Hortimix (Figura 2A). Aos vinte dias foi observado maior número de folhas nas mudas desenvolvida no Plantmax. Entretanto, deve-se observar que em todos os substratos houve aumento linear no número de folhas em função do tempo. Lédo et al. (1996) observaram que mudas de alface produzidas em bandejas de poliestireno com 288 células, no Acre, usando como substrato produtos comerciais, aos 22 dias, apresentavam 
Tabela 1. Análises química e granulométrica dos substratos Golden Mix (GM), Hortimix (HT), Plantmax (PT) e Vida Verde (VV). Campinas, IAC, 2003.

\begin{tabular}{|c|c|c|c|c|c|c|c|c|c|c|c|c|c|}
\hline \multirow{2}{*}{ Substr. } & \multirow{2}{*}{$\mathrm{pH}$} & \multirow{2}{*}{ MO (\%) } & $\mathbf{P}$ & $\mathbf{S}$ & & K & $\mathrm{Ca}$ & $\mathbf{M g}$ & $\mathrm{H}$ & Al & СТC & \multirow{2}{*}{ V (\%) } & \multirow{2}{*}{$\mathrm{C} / \mathrm{N}$} \\
\hline & & & \multicolumn{3}{|c|}{$\mathrm{mg} \cdot \mathrm{dm}^{-3}$} & \multicolumn{6}{|c|}{ mmolc. $\mathrm{dm}^{-3}$} & & \\
\hline GM & 5,5 & 89,58 & 75,0 & 193,6 & & 35,6 & 12,0 & 8,0 & 37,0 & 1,0 & 93,6 & 59,4 & 29,26 \\
\hline HT & 5,4 & 78,18 & 84,9 & 34,9 & & 10,2 & 12,0 & 7,0 & 37,0 & 1,0 & 67,2 & 43,5 & 24,93 \\
\hline PT & 6,0 & 53,13 & 82,8 & 300,0 & & 24,3 & 33,0 & 13,0 & 28,0 & 0 & 98,3 & 71,5 & 14,37 \\
\hline \multirow[t]{3}{*}{ W } & 6,0 & 54,02 & 96,9 & 193,6 & & 44,0 & 33,0 & 13,0 & 28,0 & 0 & 118,0 & 76,3 & 14,96 \\
\hline & \multirow{2}{*}{ N (\%) } & $\mathrm{Na}$ & $\mathrm{Fe}$ & Mn & $\mathrm{Cu}$ & $\mathrm{Zn}$ & B & & \multicolumn{5}{|c|}{ Abertura da peneira $(\mathrm{mm})$} \\
\hline & & \multicolumn{6}{|c|}{$\mathrm{mg} \cdot \mathrm{dm}^{-3}$} & & 2,38 & 2,00 & 0,84 & 0,42 & 0,25 \\
\hline GM & 1,78 & 83,0 & 89,3 & 34,4 & 4,7 & 8,2 & 0,3 & & 96,17 & 90,95 & 54,34 & 30,02 & 16,73 \\
\hline HT & 1,83 & 72,0 & 421,0 & 45,1 & 14,5 & 16,1 & 0,3 & & 78,06 & 69,50 & 44,18 & 25,56 & 17,05 \\
\hline PT & 2,15 & 144,0 & 163,7 & 67,7 & 5,8 & 10,2 & 0,3 & & 72,18 & 66,66 & 40,55 & 21,85 & 13,19 \\
\hline W & 2,10 & 121,0 & 297,0 & 37,0 & 4,3 & 6,7 & 0,2 & & 90,59 & 85,68 & 59,74 & 41,28 & 29,49 \\
\hline
\end{tabular}

de quatro a seis folhas definitivas. Esse número é superior aos obtidos nesse experimento onde apenas as mudas produzidas em Golden Mix e Plantmax ultrapassaram o limite inferior obtidos por esses autores. Entretanto, dados do Sebraema (sd) recomendam que o transplante seja realizado com mudas com, aproximadamente, duas a três folhas definitivas.

Em relação à estabilidade do torrão (Figura 2B), observou-se que todos os substratos foram similares aos quinze e vinte dias após a emergência das plantas. Para Golden Mix, Plantmax e Vida Verde, a estabilidade do torrão aumentou linearmente com o tempo mas, para Hortimix, houve um incremento até 16,7 dias. Tanto em bandejas de 200 como de 288 células foi observada maior estabilidade no torrão com o uso de Golden Mix (dados não apresentados). Nas bandejas com 200 células, a estabilidade do torrão com Plantmax foi inferior à Golden Mix, ao Hortimix e Vida Verde. Já em bandejas com 288 células esse fato não foi observado. Sebraema (sd) recomenda que por ocasião do transplante os torrões estejam coesos e mantenham o sistema radicular íntegro.

Não houve diferença quanto à altura média de plantas em relação ao número de células por bandeja e nem interação desta com substrato ou época de avaliação (dados não apresentados).

De maneira geral, pode-se observar que nas bandejas com 200 células em função do maior volume de substrato a

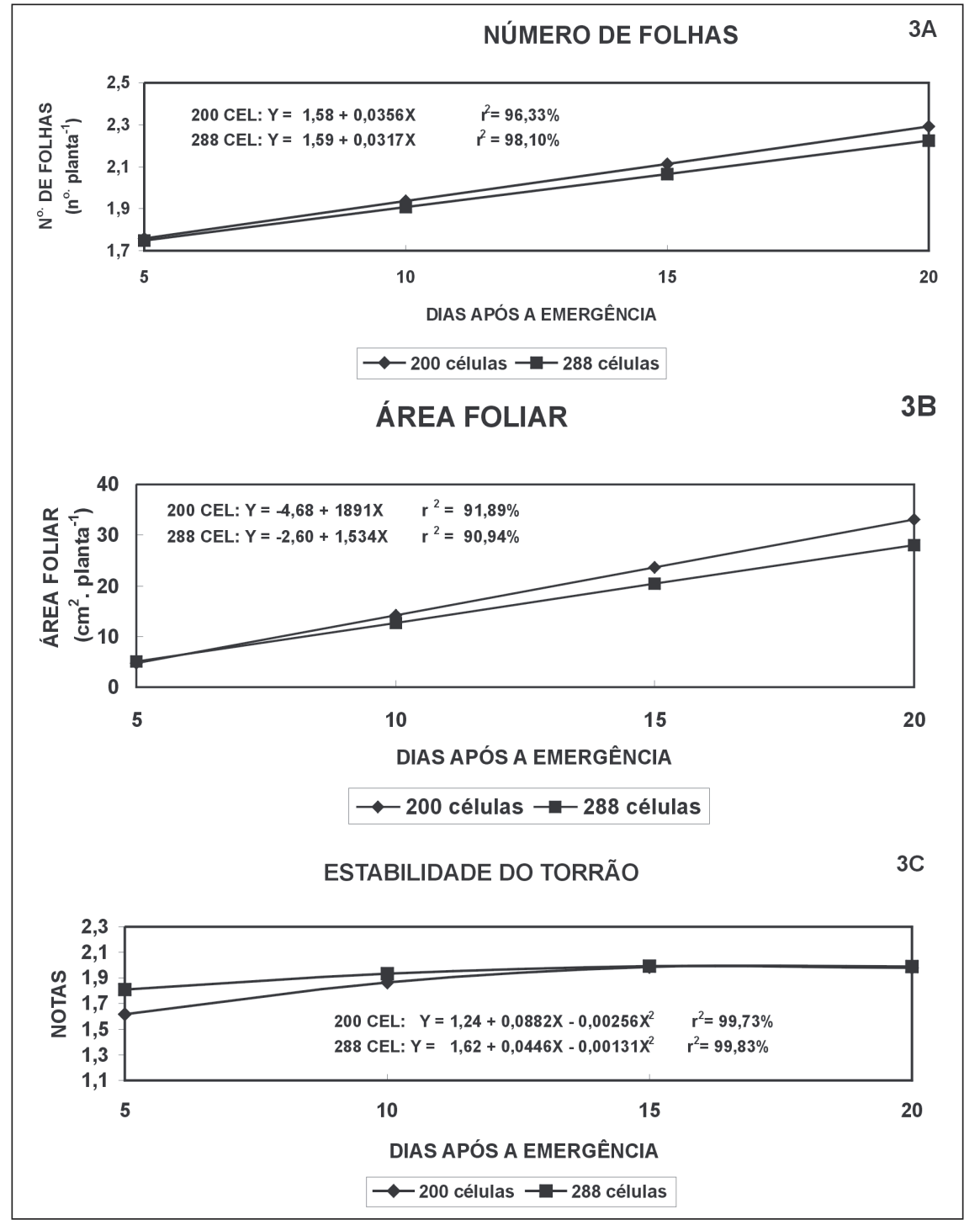

Figura 3. Número médio de folhas, área foliar por planta e estabilidade do torrão de mudas de alface em função do número de células por bandeja aos cinco, dez, quinze e vinte dias após a emergência. Os dados de número médio de folha foram transformados em raiz de $\mathrm{x}+$ 1 para a realização da análise estatística. Campinas, IAC, 2003. 
ser explorado, havia mais folhas e estas apresentaram área foliar maior que nas de 288 células (Figura 3) propiciando maior desenvolvimento. O número médio de folhas e a área foliar das mudas, independentemente do número de células, aumentaram linearmente em função do tempo (Figuras 3A e 3B).

Por ocasião do arranquio das mudas (Figura 3C), foi verificado que tanto em bandejas de 200 como de 288 células, a estabilidade do torrão cresceu em função do tempo e atingiu um máximo aos 17 dias.

Comparando-se o comportamento do substrato em função do número de células por bandeja, verificou-se que para Hortimix, Plantmax e Vida Verde, a estabilidade foi maior em bandejas com 288 unidades. Jungk (1975), citado por Menezes Júnior et al. (2000), verificou que em células menores como ocorre com aquelas com 288, há menor espaço disponível para o desenvolvimento da mudas e fica mais difícil o suprimento de fatores como água, ar e nutrientes, que otimizem a produção e que garantam o desenvolvimento e o crescimento normal das mudas. Salvador et al. (2001) relataram que em células de tamanho menor, em conseqüência da maior concentração de raízes, há maior demanda de oxigênio e de remoção de $\mathrm{CO}_{2}$. Mudas crescidas em células menores ficam mais vulneráveis ao estresse hídrico pois a quantidade de substrato nem sempre é suficiente para a retenção adequada de água para a manutenção da turgidez (Rozza e Teres, 1985 citados por Barros, 1997). Há então necessidade de maior freqüencia de irrigação para suprir a demanda de água e para sustentar altas taxas de crescimento num volume muito restrito. Entretanto, a irrigação mais constante torna o substrato mais sujeito à lixiviação de nutrientes.
De maneira geral, tanto em bandejas de 200 como de 288 células, verificou-se superioridade do substrato Plantmax em quase todos os fatores estudados. Entretanto, os demais substratos apresentando plantas de menor porte podem se mostrar interessantes quando o produtor de hortaliças necessita atrasar o plantio em alguns dias por fatores como excesso de chuva e problemas de mão-de-obra o que ocorre com certa freqüencia na região de Campinas.

Pode-se concluir que, de modo geral, o substrato Plantmax, proporcionou mudas de alface com maior altura, área foliar e número de folhas em relação aos outros substratos. Independente do tipo de substrato, as bandejas de 200 células mostraram-se melhores que as de 288 células quanto ao número de folhas e área foliar, por ocasião do transplante (20 dias). Em ambos os tipos de bandejas (200 e 288 células), verificou-se a mesma estabilidade do torrão aos $15 \mathrm{e}$ 20 dias após a emergência das plantas de alface.

\section{AGRADECIMENTOS}

Os autores agradecem a Antonio Takao Hangui (Tomatec Agro Comercial Ltda.), Ricardo Mikami (Vegetal Agro Comercial) e Nayde Machado (Planalto Agrosciences Ltda.) pela cessão dos substratos utilizados nesse experimento. Os agradecimentos são também extensivos ao Laboratório Agronômico S/C Ltda. (LAGRO) pelas análises físico-químicas realizadas.

\section{LITERATURA CITADA}

BARROS, S.B.M. Avaliação de diferentes recipientes na produção de mudas de tomate (Lycoperisum esculentum L.) e pepino (Cucumis sativus L.). Piracicaba: ESALQ/USP. 1997. 70 p. (Tese mestrado).
CAÑIZARES, K.A.; COSTA, P.C.; GOTO, R.; VIEIRA, A.R.M. Desenvolvimento de mudas de pepino em diferentes substratos com e sem uso de solução nutritiva. Horticultura Brasileira, Brasília, v.20, n.2, p.227-229, 2002

CARRIJO, O.A., LIZ, R.S.; MAKISHIMA, N. Fibra de casca de coco verde como substrato agrícola. Horticultura Brasileira, Brasília, v.20, n.4, p.533-535, 2002.

ECHER, M.M.; ARANDA, A.N.; BORTOLAZZO, E.D.; BRAGA, J.S.; TESSARIOLI NETO, J. Efeito de três substratos e dois recipientes na produção de mudas de beterraba. Horticultura Brasileira, Brasília, v.18, suplemento, p.509-511, 2000.

FURLANI, P.R.; BOLONHEZI, D.; SILVEIRA, L.C.P.; FAQUIN, V. Nutrição mineral de hortaliças, preparo e manejo de soluções nutritiva. Informe Agropecuário, Belo Horizonte, v.20, n.200/ 201, p.90-98, 1999.

GRUSZYNSKI, C. Resíduo agro-industrial "casca de tungue" como componente de substrato para plantas. Porto Alegre: UFRGS. 2002. p. 41. (Tese mestrado)

LÉDO, F.J.S.; SOUZA, J.A.; SIVIERO, A.; ARAÚJO, H.M.; SILVA, M.R. Introdução e avaliação de cultivares de alface (Lactuca sativa $L$.) para o período seco no Acre. Rio Branco: EMBRAPA/ Centro de Pesquisa Agroflorestal do Acre. 1996. 4p. (Pesquisa em Andamento, 87).

LUZ, J.M.; PAULA, E.C.; GUIMARÃES, T.G. Produção de mudas de alface, tomateiro e couveflor em diferentes substratos comerciais. Horticultura Brasileira, Brasília, v.18, suplemento, p.579-581, 2000.

MENEZES JÚNIOR, F.O.G.; FERNANDES, H.S.; MAUCH, C.R.; SILVA, J.B. Caracterização de diferentes substratos e seu desempenho na produção de mudas de alface em ambiente protegido. Horticultura Brasileira, Brasília, v.18, n.3, p.164-170, 2000.

OLIVEIRA, R.P.; SCIVITTARO, W.B.; VASCONCELLOS, L.A.B.C. Avaliação de mudas de maracujazeiro em função do substrato e do tipo de bandejas. Scientia Agricola, Piracicaba, v.50, n.2, p.261-266, 1993.

SALVADOR, E.D.; PAQUAL, M.; SPERA, M.R.N. Efeito de diferentes substratos no crescimento de samambaia-matogrossense (Polypodium aureum L.) Ciência Agrotécnica, Lavras, v.25, n.4, p.1006-1011, 2001.

SEBRAEMA, Maranhão. Diagnóstico hortaliças: alface. Disponível Em: http:// www.sebraema.com.br/pages/pesquisa/ page_horta_alface.htm. Consultado em: 14/0103. SILVEIRA, E.B.; RODRIGUES, V.J.L.B.; GOMES, A.M.A.; MARIANO, R.L.R.; MESQUITA, J.C.P. Pó de coco como substrato para produção de mudas de tomateiro. Horticultura Brasileira, Brasília, v.20, n.2, p.211-216, 2002. 